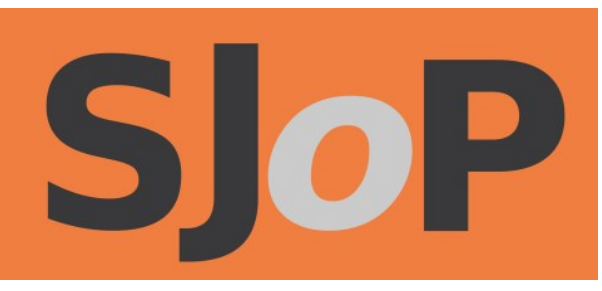

Performance review: -ish, by Aby Watson

\title{
TIMOTHY COOPER
}

The Scottish Journal of Performance

Volume 6, Issue 1; July 2019

ISSN: 2054-1953 (Print) / ISSN: 2054-1961 (Online)

Publication details: http://www.scottishjournalofperformance.org

To cite this article: Cooper, T., 2019. Performance review: -ish, by Aby Watson. Scottish Journal of Performance, 6(1): pp.85-90.

To link to this article: http://doi.org/10.14439/sjop.2019.0601.06

This work is licensed under a Creative Commons Attribution 4.0 International License. See

http://creativecommons.org/licenses/by/4.0/ for details. 


\section{Performance review: -ish, by Aby Watson}

TIMOTHY COOPER

DOI: 10.14439/sjop.2019.0601.06

Publication date: 14 July 2019

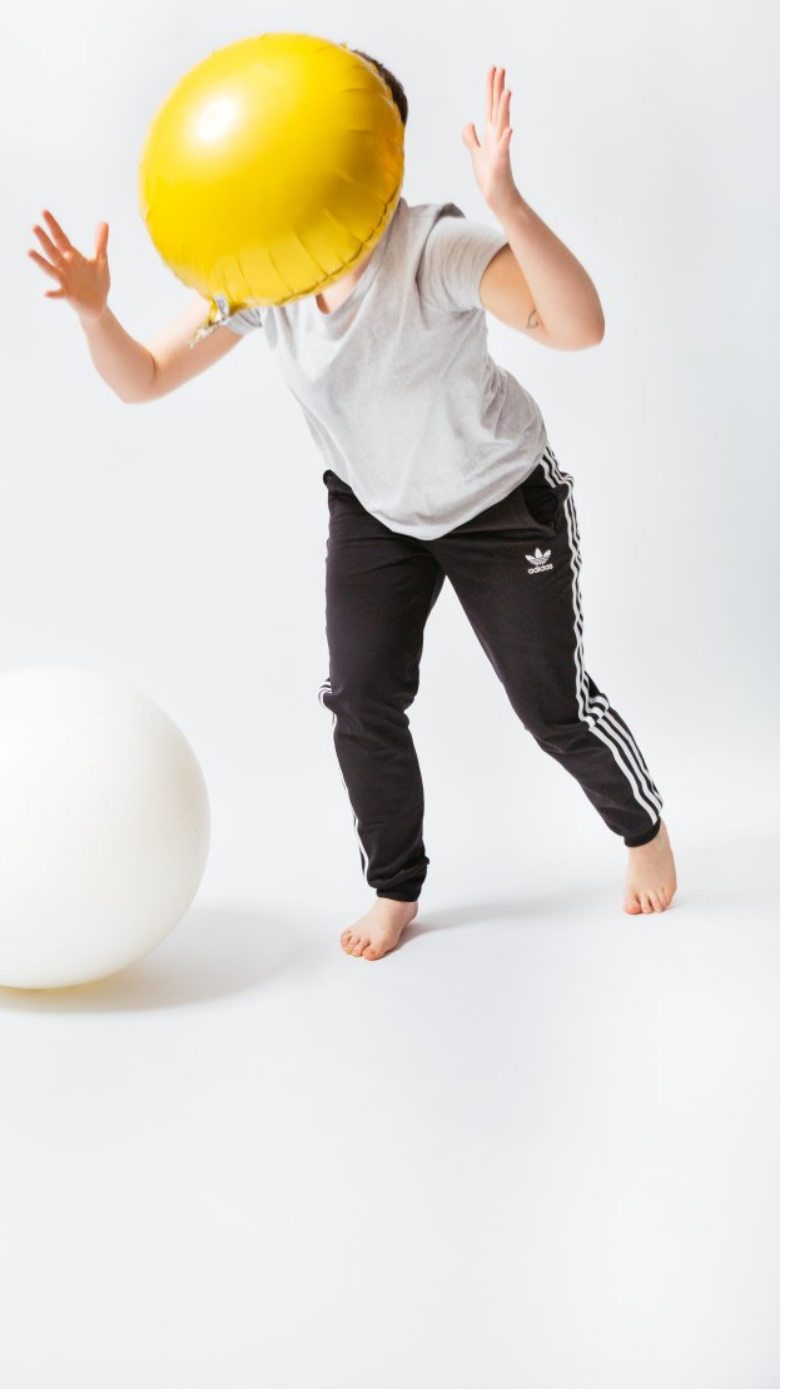

Photo: Jassy Earl Photography 
Scottish Journal of Performance

Volume 6, Issue 1

Saturday 19 October 2018, Tramway, Glasgow

Performers:

Dancer: Aby Watson

BSL interpreter: Amy Cheskin

\section{Introducing -ish}

In October 2018 Aby Watson presented her work -ish at the Tramway in Glasgow. The work explores

... choreography of movement, text and object exploring the murky territory that dyspraxia inhabits between the simple dichotomy of able/disabled. Made and performed by a dyspraxic artist... -ish is a dyspraxic performance of real effort (and momentary chaos) which forms an unapologetic exploration of inbetween-ness that flourishes with and thrives on dys-function (Watson, 2018).

The performance given by Watson and interpreted into BSL by Amy Cheskin was arresting, moving and highly thoughtful. The feeling of the work was characterised by the two performance states Watson creates in -ish. A box was painted on the floor and when Watson entered this space she was 'performing in a formal sense'. Outside of the box she was not performing in the sense of a 'formal' performance: she was performing self, revealing aspects of the creative process through conversational explanations made directly to the audience. Richard Schechner (2013, p.38) argues, '[t]here are limits to what "is" performance. But just about anything can be studied "as" performance". There is not the same manneredness in the out-of-the-box moments as when Watson 'is' performing within the box. This sense of opposition between 'is' and 'as' performance states raises the tension at any point Watson enters the box and allows this to dissipate as soon as she leaves it, and the performance becomes more fragile. 
There were three aspects that I found particularly interesting in this work;

\section{1. -Inherent Choreographies}

Throughout the work Watson performed a series of duets with a variety of objects, notably a space hopper and helium balloons, that explored the inherent motion of these objects. The sight of a helium balloon slowly 'dancing' around the space, occasionally blown by a fan, provided a particularly fascinating play on chance and indeterminacy-every time the balloon seemed to be losing energy it found itself caught in a gust from the fan and gently continued its playful movements around the space. The exploration of the space hopper was more conscious, but no less interesting; Watson used the space hopper to showcase a learnt virtuosity. In her writing she has discussed the problem of virtuosity in her creative work (Watson, 2017). What does it mean for a dyspraxic dancer who identifies as being clumsy and chaotic to master and carefully control movement? Is this contrary to her intent? The answer to this will, I suspect, emerge through future work. But here the mannered and impressive control of the space hopper, as Watson bounced around the box performing perfect 90-degree turns, contrasted beautifully with the chaos of the space hopper thrown against the wall bouncing, sometimes dangerously, back towards Watson.

The movements or 'dances' that the objects undertake become choreography through the framing of the work. It is in the precise parameters, carefully created by Watson, that this occurs. Outside of the world of -ish these movements might be fun, or playful; inside the world of -ish they take on far greater significance. 


\section{Self objectification}

If we are so focussed on the objects in the work, what does that mean for our engagement with Watson as a performer in this space? In the work she seems to use the same choreographic intent to organise her own movements and the objects she works with. Does this make Watson an object within her own work? It certainly means that Watson could be read in an objectified way. Her work focusses on her inherent characteristics and makes the fragilities of her dyspraxia and dyslexia explicit. -ish is not a work where barriers between performer and audience are felt. Watson draws us into the work and presents it in a manner that amplifies and heightens the specific qualities of her movements, celebrating both her clumsiness and her creative exploration of this. All of this adds up to make it impossible to ignore the self in this work.

\section{ExHaustion}

The way the work deals with exhaustion is particularly moving. Watson danced herself to the point of exhaustion in each of the first two sequences; would she sustain this to the end of the work, ending every sequence in exhaustion? As the work progressed it became clear this was not going to be the case and Watson explored a variety of ways of ending sequences. -ish beautifully foregrounds difference, diversity and disability, and as the work ended, I found myself wondering if the moments of exhaustion could be read as a metaphor for the exhaustion expressed by minority groups as they make the case for greater equality in the twenty-first century. A criticism I might make is of the way this exhaustion is paced in the work. Much of the energy is front-loaded and reimagining the sequencing might allow some of the more frenetic energy to be interspersed. This might lead to a more satisfying pacing. However, if -ish is about exhaustion and dissipating energy this might not be in keeping with the content and intent of the work. 


\section{A few words on British Sign Language Interpretation}

In a work centred on diversity, it is important to discuss the BSL interpretation. Amy Cheskin's performance went well beyond translating Watson's speech and the incidental music into BSL language. The interpretation provided a counterpoint to Watson's movement as Cheskin translated the musical and spoken content into a different kind of movement language.

This was made up of Cheskin shadowing Watson around the edges of the space, interpreting her spoken parts and miming a variety of musical instruments that made up the arrangements of the music. Cheskin's body language perfectly matched the understated and conversational tone of the spoken parts, interpreting Watson's manner very effectively. In her interpretation of the music Cheskin's movement perfectly translated its vigorous energy - there was an air of believability in the miming of the different instruments, which was a highlight. If Watson embodied her diversity, then Cheskin embodied the musical personality of the work: the way the two performers interacted was similarly effective with some wonderfully choreographed moments.

\section{References}

Schechner, R., 2013. Performance studies: an introduction. London: Routledge.

Watson, A., 2017. Not [sic]: Choreographing a radically affirmative perspective of dyspraxia. CUK Research Student's Conference. The Royal Conservatoire of Scotland.

Watson, A., 2018. -ish. [online] Available at:

<http://www.abywatson.co.uk/work\#/-ish/> [Accessed 27 Nov. 2018].

\section{About the review author}

TIMOTHY COOPER is a composer and performer of electroacoustic music. In his music he explores new contexts for the sounds he works with. He uses microphones as sonic microscopes and loudspeakers to amplify and heighten the qualities of the sounds he 
Scottish Journal of Performance

Volume 6, Issue 1

records. Recent projects include the site-responsive installation Tide Times made with Laura Bissell and Breathing Space for tuba and electronics composed for Danielle Price.

Tim is a PhD candidate at the Royal Conservatoire of Scotland, supervised by Professor Alistair MacDonald and Dr Diana Salazar. He lectures at the Royal Conservatoire of Scotland and at Edinburgh College. 